\title{
Geografia da inovação: o debate contemporâneo sobre a relação entre território e inovação
}

La géographie de l'innovation: le débat contemporain sur les rapports entre territoire et innovation

Geography of innovation: the contemporary debate the relationship territory and innovation

Geografía de la inovación: el debate contemporáneo de la relación territorio e innovación

\section{Regina Tunes}

\section{CpenEdition}

\section{Journals}

Edição electrónica

URL: http://journals.openedition.org/espacoeconomia/2410

DOI: $10.4000 /$ espacoeconomia.2410

ISSN: 2317-7837

Editora

Núcleo de Pesquisa Espaço \& Economia

Refêrencia eletrónica

Regina Tunes, « Geografia da inovação: o debate contemporâneo sobre a relação entre território e inovação », Espaço e Economia [Online], 9 | 2016, posto online no dia 19 janeiro 2017, consultado o 24 março 2020. URL : http://journals.openedition.org/espacoeconomia/2410 ; DOI : https://doi.org/ 10.4000/espacoeconomia.2410

Este documento foi criado de forma automática no dia 24 março 2020.

(C) NUPEE 


\title{
Geografia da inovação: o debate contemporâneo sobre a relação entre território e inovação
}

\author{
La géographie de l'innovation: le débat contemporain sur les rapports entre \\ territoire et innovation \\ Geography of innovation: the contemporary debate the relationship territory \\ and innovation \\ Geografía de la inovación: el debate contemporáneo de la relación territorio e \\ innovación
}

\section{Regina Tunes}

\section{Introdução}

1 A Geografia Econômica, área de estudo e pesquisa tradicional da Geografia que busca, em linhas gerais, a compreensão da relação entre espaço e economia, tem apresentando crescimento em sua produção intelectual e científica e de certo, como aponta Paul Claval (2005), isso está associado as recentes transformações no mundo do trabalho, a intensificação dos fluxos internacionais de mercadorias, pessoas, informação e capitais e a metropolização do espaço.

2 Certamente novos desafios teóricos e metodológicos se impõem sobre a análise da dimensão espacial da dinâmica econômica em diversas escalas geográficas. Isso impele rigor conceitual e a compreensão das determinações, no sentido do que é o mais significativo, para a compreensão dos processos e fenômenos que interessa à análise da geografia econômica.

Dentre os novos desafios teóricos da geografia econômica em estreita relação com as transformações do mundo do trabalho que Claval (2005) destacou em seu texto certamente está a compreensão do que vem sendo denominado recentemente de 
geografia da inovação. Longe de se constituir uma área específica de pesquisa na geografia, essa abordagem teórica aprofunda a compreensão da relação espaço e economia a partir do paradigma da inovação.

De forma mais específica podemos afirmar que a geografia da inovação se constitui de pesquisas que analisam a relação dialética entre inovação e território a partir da constituição de redes de inovação que são territorializadas em seletivos espaços em diversas escalas geográficas.

5 O objetivo central desse texto é justamente apresentar e discutir o debate teórico recente da geografia da inovação centrando nossa análise nas contribuições teóricas mais relevantes. Essas contribuições, denominadas por Moulart e Sekia (2003) como sistemas territoriais de inovação, constituem como centrais nessa linha de pesquisa e evidenciam a importância de um olhar desde a Geografia para a compreensão dos processos de inovação no capitalismo atual.

6 Inovação é entendida como a criação do novo e/ou algo substancialmente melhorado que pode ser um produto novo, um processo de produção original, uma forma de organização da empresa inédita ou um marketing singular.

7 Como já destacamos anteriormente, o crescimento recente da importância da inovação no capitalismo contemporâneo guarda estreita relação com as mudanças no mundo do trabalho, especialmente a partir da reestruturação produtiva que evidencia, como sabemos, a crise do capital produtivo que busca outras formas mais eficazes de valorização.

8 Dentre as possibilidades de rotação mais veloz do capital após a crise do modelo fordista de produção emerge a relevância dos processos de inovação. Isso não significa dizer que a inovação se constitua de total novidade nos rumos da reestruturação produtiva.

9 Inovação que não é nova parece, a um primeiro olhar, uma contradição de termos. Mas é fundamental destacar que toda e qualquer sociedade, em tempos históricos distintos, sempre inovou, a inovação está associada aos principais avanços da sociedade que já foi o fogo na Idade Antiga à máquina à vapor na Revolução Industrial. Assim, a inovação teve continuamente um papel importante no desenvolvimento e na garantia da reprodução do capital.

10 Apesar de não se constituir uma novidade, o que estamos chamando a atenção é que há hoje uma significativa aceleração inovativa, no sentido de que a inovação passa a ser algo mais presente e com uma velocidade cada vez maior nas relações sociais de produção e que isso está intrinsicamente associado ao processo de reestruturação produtiva.

11 Para realizar esse debate o texto inicia com a discussão da relação entre território e inovação em que apresentamos as três contribuições teóricas - novos espaços industriais, meio inovador e sistemas de inovação - que podem ser analisados a partir da perspectiva dos sistemas territoriais de inovação (Moulart e Sekia, 2003). Nessa primeira parte evidenciamos brevemente os pontos singulares dessas perspectivas teóricas, os autores que possuem pesquisas a partir dessa abordagem, bem como os apontamentos críticos que se apresentam a cada uma delas.

12 Na segunda parte, que se constitui no eixo central de nosso debate, realizamos um diálogo entre as três perspectivas com o objetivo de ressaltar alguns pontos 
convergentes nessas contribuições que perpassa questões como a territorialização do capital inovador e a produção de redes de inovação.

\section{Território e Inovação}

13 O estudo da relação entre território e inovação não se constitui uma novidade na Geografia. Assim como já afirmamos que a inovação faz parte do processo de reprodução das relações sociais de produção, mas que na atualidade se apresentam de forma cada vez mais veloz, podemos também referenciar a essa mesma perspectiva em relação aos estudos da dimensão territorial da inovação.

Certamente um dos precursores desses estudos foi o geógrafo sueco Torsten Hägerstrand que na década de 1950 e 1960 analisou o fenômeno da difusão espacial da inovação a partir de um modelo por ondas baseado em uma aproximação probabilística entre emissores e receptores da inovação.

A pesquisa de Hägerstrand abordou especialmente a difusão da inovação do automóvel da Scania e do rádio pela região do norte da Suécia. $O$ autor concluiu nessa pesquisa que "a hierarquia urbana direciona o curso da difusão"1 e que é nos grandes centros urbanos suecos que a inovação aparece primeiro e que a partir daí ela se difunde de acordo com a hierarquia urbana.

o pioneiro trabalho do geógrafo sueco foi bastante criticado na Geografia por conta de sua aproximação à modelos matemáticos e à geografia quantitativa. Ainda assim acreditamos que se constitui em contribuição significativa para a compreensão da relação entre técnica e espaço que é fundamentalmente o olhar que Hägerstrand apresenta de maior relevância em suas pesquisas.

Mais recentemente os debates a partir dessa perspectiva tiveram substancial crescimento nas ciências humanas e sociais aplicadas a partir de uma variedade muito grande de matrizes teóricas e metodológicas. Não temos a intenção aqui de destacar todas essas contribuições, mas sim de debater aquelas que possuem uma preocupação centrada na territorialização da produção inovadora.

Storper (1994) apresenta na citação abaixo uma consideração interessante que sintetiza nossa compreensão nesse texto sobre o processo de territorialização.

(...) uma atividade é territorializada quando sua efetivação econômica depende da localização (dependência do lugar), e quando tal localização é específica de um lugar, isto é, tem raízes em recursos não existentes em muitos outros espaços ou que não podem ser fácil e rapidamente criados ou imitados nos locais que não os têm. ${ }^{2}$

19 Dentro dessa visão o texto vai aprofundar a análise de três abordagens teóricas ligadas ao que Moulart e Sekia ${ }^{3}$ denominaram de sistemas territoriais de inovação definidos pelos autores como "is used as a generic name for models of regional innovation in wich local institutional dynamics play a significant role".

As três abordagens teóricas são: 1) o modelo francês do meio inovador criado pelo GREMI (Groupe de Recherche Européen sur les Milieux Innovateurs); 2) os sistemas de inovação que podem ser locais, regionais e nacionais criados primeiramente a partir de Freeman (1987); 3) os novos espaços industriais que abordam uma série de outros conceitos e são originários da Escola Californiana de Geografia Econômica que tem Scott e Storper (1988) como seus dois principais colaboradores. 
21 Destacamos no quadro 1 os autores mais importantes, os principais conceitos alinhados a cada teoria, a escala geográfica mais utilizada nas pesquisas, o argumento central para a compreensão da relação território e inovação e as principais críticas que são apresentadas no recente debate acadêmico em torno da Geografia da Inovação.

Evidentemente a apresentação de forma esquemática do quadro generaliza demais as três contribuições teóricas, por isso está longe de apresentar com aprofundamento ${ }^{4}$ que mereceria cada uma das teorias, no entanto constitui-se em um esforço de síntese do que consideramos mais relevante de cada uma delas para o debate da relação território e inovação.

23 Após o quadro apresentamos breve discussão dos conceitos fundamentais de cada abordagem teórica e as críticas mais relevantes na discussão da geografia da inovação. A ideia aqui, nesse primeiro momento, é denotar o que diferencia cada abordagem teórica.

24 Posteriormente a esta exposição dos conceitos fundamentais e das principais críticas aprofundaremos o debate com o que que une essas três perspectivas na proposição de uma geografia da inovação destacando especialmente a formação de redes de inovação e a seletividade espacial.

Quadro 1 - Síntese e limites das principais teorias dos sistemas territoriais de inovação

\begin{tabular}{|c|c|c|}
\hline $\begin{array}{l}\text { Novos espaços industriais } \\
\text { (NEI) }\end{array}$ & Meios Inovadores & $\begin{array}{l}\text { Sistemas Nacionais de } \\
\text { Inovacão (SNI) }\end{array}$ \\
\hline 8 & 8 & 8 \\
\hline $\begin{array}{l}\text { Conceitos relacionados: } \\
\text { janelas de oportunidade de } \\
\text { localização e desintegração } \\
\text { vertical. }\end{array}$ & $\begin{array}{l}\text { Autores: Aydalot, Maillat, } \\
\text { Crevoisier, Quévit. } \\
\text { Conceitos relacionados: } \\
\text { aprendizagem coletiva, } \\
\text { redes, lógica territorial. } \\
\text { Escala Geográfica: Escala } \\
\text { local. }\end{array}$ & $\begin{array}{l}\text { Autores: Freeman, Lundvall, } \\
\text { Edquist, Morgan } \\
\text { Conceitos relacionados: } \\
\text { modelo interativo de } \\
\text { inovação, cooperação, } \\
\text { pathdependece. } \\
\text { Escala Geográfica: Escala } \\
\text { regional. }\end{array}$ \\
\hline $\begin{array}{l}\text { Escala Geográfica: } \\
\text { Abordagem interescalar. } \\
\text { Argumento: a aglomeração } \\
\text { industrial relaciona-se as } \\
\text { estratégias flexiveis de } \\
\text { produção e diminuem os } \\
\text { custos de transação entre as } \\
\text { empresas, permitindo a } \\
\text { formação de redes de } \\
\text { empresas e aprofundando a } \\
\text { divisão social do trabalho. } \\
\\
\text { Críticas: as causas da } \\
\text { formação dos NEls são } \\
\text { atribuidas a formações } \\
\text { espontâneas e quase }\end{array}$ & $\begin{array}{l}\text { Argumento: } 0 \text { meio detém } \\
\text { um papel gerador de } \\
\text { efeitos dinâmicos } \\
\text { inovadores especialmente } \\
\text { pela existência de } \\
\text { processos de aprendizagem } \\
\text { coletivos e de redução da } \\
\text { incerteza e do risco } \\
\text { associado à inovação. } \\
\text { Críticas: Teoria tautológica, } \\
\text { pouca atenção aos } \\
\text { processos globais não } \\
\text { centrados no nivel local. } \\
\text { Pouca atenção ao papel do } \\
\text { Estado. }\end{array}$ & $\begin{array}{l}\text { Argumento: Análise } \\
\text { tripartida dos agentes de } \\
\text { inovação: universidade, } \\
\text { mercado e Estado. As } \\
\text { dinâmicas de inovação estão } \\
\text { fortemente centradas no } \\
\text { trajeto tecnológico da } \\
\text { região. } \\
\text { Críticas: Teoria construída a } \\
\text { partir de uma política estatal } \\
\text { e institucional. Subentende o } \\
\text { conceito de região por ele } \\
\text { mesmo e não como uma } \\
\text { construção intelectual. }\end{array}$ \\
\hline
\end{tabular}

Fonte: TUNES, 2015

Iniciaremos a concisa apresentação com a discussão dos novos espaços industriais. Essa abordagem é originada da Escola Californiana de Geografia Econômica que a partir de uma abordagem regulacionista procura compreender as relações território e inovação tendo como marco temporal o processo de reestruturação produtiva. 
O foco central da discussão dos pesquisadores associados a esse grupo, indicados no quadro 1, é o Sillicon Valey na Califórnia no EUA, ainda que tenham trabalhos que analisam também o corredor Route 128 em Boston, Fairchild em São Francisco, dentre outras áreas que possuem em comum a concentração geográfica de empresas inovadoras de ramos industriais de alta tecnologia.

Dois conceitos são fundamentais para a compreensão da abordagem dos novos espaços industriais. O primeiro, originário da escola regulacionista e que tem Georges Benko (1995) como um dos principais pesquisadores que aprofundaram essa temática, é o de desintegração vertical. 0 segundo bastante associado as pesquisas de Michael Storper e Allen Scott (1987) é de janelas de oportunidade.

A desintegração vertical significa um aprofundamento da divisão social do trabalho típica do momento da reestruturação produtiva. Segundo Benko ${ }^{5}$ "fala-se em desintegração vertical de uma empresa quando as diferentes etapas da produção não se efetivam na mesma empresa".

Caracteriza-se pela especialização das empresas em certa etapa do processo produtivo, o que vem multiplicando as pequenas empresas. Essas estabelecem contratos ou mesmo parcerias com as grandes empresas ${ }^{6}$, criando uma relação de interdependência entre elas. A grande empresa necessita dos serviços e produtos fabricados pela pequena empresa, e a pequena necessita dessa demanda por seus serviços da grande.

A desintegração vertical, assim, origina as relações de cooperação entre as empresas e entre demais instituições que estão presentes na região dando forma as redes de cooperação. Aqui a proximidade geográfica e/ou organizacional possui relevância na diminuição dos custos de transação entre as empresas.

O segundo conceito que vamos destacar na análise da relação território e inovação dos novos espaços industriais é o de janela de oportunidade. Vale (2009) ${ }^{7}$ sintetiza a expressão afirmando que são "fatores acidentais, associados a determinados contextos espacio-temporais específicos".

Storper e Walker (1989) afirmam que o conceito de janelas de oportunidade faz referência a momentos de relativa liberdade de localização das indústrias de alta tecnologia, foco central dessa linha de pesquisa como já destacamos anteriormente, uma vez que as inovações seriam o meio pelo qual estas atividades se libertam de limites impelidas por insumos de produção.

3 Em síntese, devemos então entender que os novos espaços industriais estão relacionados ao processo de desintegração vertical, ligado as estratégias da reestruturação produtiva e da flexibilidade da produção, mas que, no entanto, se relaciona também a uma ideia de espontaneidade do sistema produtivo.

34 Esse último aspecto relacionado ao conceito de janelas de oportunidade é o foco central da crítica que se faz a abordagem teórica dos novos espaços industriais. Vale (2009) e Sternberg (1996) apontam que tratar da localização da empresa inovadora como um evento arbitrário, ligado a espontaneidade do sistema produtivo, não contribui para o estabelecimento de políticas públicas que possam favorecer o desenvolvimento regional.

Sternberg (1996) acrescenta, nesse mesmo sentido, que tratar da localização da empresa inovadora como uma questão aleatória faz com que o corpo teórico dessa abordagem não se sustente e não permita abstrações a partir de outra região. 

local na sua relação com outras escalas geográficas já que ele aponta que as economias locais são "as bases territorial de partes das cadeias e não as localizações de espaços econômicos completos".

denominou de estudos localistas ${ }^{10}$ afirmando que são desconsideradas as relações interescalares entre os fenômenos globais e locais, ou seja, desconsidera-se na abordagem dos meios inovadores o que existe entre a escala global e local.

Os estudos localistas avaliam as vantagens aglomerativas e de proximidade como fontes de conhecimento e aprendizagem, enraizadas naquele território singular, criando, com suas investigações, listas ad hoc dos ativos, capacitações, normas, rotinas e hábitos, todos devidamente region-specific. Muitos desses trabalhos negligenciam que há hierarquias inter-regionais, e o comando maior desses processos, geralmente, está fora do espaço sob análise ${ }^{11}$.

O segundo grupo de pesquisadores é do modelo francês de millieux innovateurs. Essa abordagem foi elaborada por um grupo de pesquisadores europeus e norteamericanos do GREMI (Groupe de Recherche Européen sur les Millieux Innovateurs), na Suíça, criado em 1984 por Philippe Aydalot, que concebe, em linhas bem gerais, o meio como uma incubadora da inovação.

constitui como

(...) um conjunto territorializado no qual as interações entre os agentes econômicos se desenvolvem por meio da aprendizagem que eles fazem das transações multilaterais geradoras de externalidades específicas à inovação e pela conjunta dos recursos 8 .

abordagem. Em primeiro lugar o papel das interações dos agentes econômicos envolvidos no processo de inovação, segundo a relevância do processo de aprendizagem e, em terceiro, a imbricação entre os agentes e os processos de aprendizagem na geração de externalidades que são importantes à inovação. pois esses três elementos estão presentes e une, na verdade, as abordagens teóricas que estamos aqui destacando.

teóricas é a questão escalar abordada nessa perspectiva. Enquanto nos novos espaços industriais e nos sistemas nacionais/regionais/locais de inovação há um tratamento interescalar mais frequente, nos meios inovadores o grande destaque é a escala local.

exatamente sobre esse aspecto. Benko (1995) e Scott e Storper (1988) apontam que a fragilidade mais significativa dessa abordagem é a pouca relação que os autores estabelecem com o contexto global e com o mercado internacional a que a inovação está inserida.

andão (2012) também aponta como uma vulnerabilidade da abordagem dos meios inovadores a insuficiência de análise da atuação do Estado na constituição dos meios inovadores. O que aparece frequentemente, e é apontada como exígua por Brandão 
(2012), é a perspectiva da governança na análise do estabelecimento de parcerias público-privado no planejamento e gestão dos meios inovadores.

O que chama mais a atenção em relação a esse último apontamento crítico no corpo teórico dos meios inovadores é justamente o fato da análise empírica ser recorrente sobre os parques tecnológicos e tecnopolos que são formas urbanas essencialmente planejadas pelo Estado, ainda que em muitos casos em parceria com o capital privado. Por último nessa breve apresentação os Sistemas Nacionais de Inovação (SNI). Essa expressão foi criada por Christopher Freeman no final dos anos 1980 e possui estreita relação com a obra de Joseph Schumpeter. Outros pesquisadores que também possuem abordagem nessa linha de pesquisa são Lundvall (2005) e Edquist (1997).

Systems of innovation, defined as a set of different institutions that contribute to the development of the innovation and learning capacity of a country, region, economic sector or locality, comprises a series of elements and relations that relate production, assimilation, use and diffusion of knowledge. In other words, innovative performance depends not only on firms and R\&D organizations performance but also on how they interact, among them and other agents, as well as all the other forms by which they acquire, use and diffuse knowledge. Innovation capacity derives, therefore, from the confluence of social, political, institutional, and cultural specific factors and from the environment in which economic agents operate. $^{12}$

$\mathrm{Na}$ citação acima gostaríamos de destacar dois pontos que consideramos fundamentais para a compreensão do SNI. O primeiro destaque é a ação articulada entre diversos agentes associados à inovação que geralmente envolvem o Estado, a sociedade e o capital privado. $O$ segundo é ressaltar a questão interescalar que nos parece muito clara no trecho acima. Sobre este destaque, vale apontar que o corpo teórico do que generalizamos como SNI envolvem análises escalares nacionais, regionais e locais. Em todas as escalas empíricas de análise há a relação interno-externo presente a partir da perspectiva do estudo das relações de proximidade e também de fluxos internacionais.

48 A abordagem do SNI possui uma maior aderência na academia e nas políticas públicas do que as demais abordagens teóricas. Isso pode ser evidenciado não apenas pela quantidade de trabalhos publicados em vários países do mundo que fazem referência ao conceito de SNI, como também pelo uso desse arcabouço teórico nas pesquisas oficiais públicas de vários países do mundo, inclusive o Brasil, e também de instituições supranacionais como a Organização de Cooperação para o Desenvolvimento Econômico (OCDE).

49 As críticas apontadas a perspectiva do SNI são, segundo Vale (2009), baseadas em duas linhas de reflexão: a primeira mais política pela aproximação institucional dessa abordagem com as políticas estatais, e a segunda de ordem epistemológica pela concepção de região que está presente nessa abordagem.

De forma bem concisa podemos indicar que a primeira crítica aponta que a proliferação de estudos que levam em consideração a abordagem do SNI ocorreu pela grande aceitação de tal perspectiva pelo Estado e pelas políticas públicas.

51 Na segunda linha da crítica ao SNI que aproxima mais de uma questão de fragilidade conceitual da abordagem, Shearmur (2008) aponta um aspecto neorregionalista desses estudos por considerar a região o ponto de partida para a pesquisa empírica. E, dessa forma, desconsiderar que a região não é algo natural e sim uma construção intelectual do pesquisador. 
52 Apontamos até aqui as questões singulares das três perspectivas teóricas da relação inovação e território que estamos analisando no texto. Relevante destacar ainda que parte das diferenças teóricas nas abordagens certamente se relaciona com as distintas áreas de formação e de desenvolvimento das pesquisas que envolvem desde a própria Geografia até a Economia, Sociologia, Administração e Engenharia.

53 O interessante a se acentuar para finalizar essa parte do texto é o quanto a multidisciplinaridade está presente nos estudos da inovação e o quanto essa visão multi a partir de uma problemática de pesquisa contribui de forma mais intensa para a compreensão do objeto de pesquisa.

\section{0 que une as três perspectivas teóricas: as redes territorializadas de inovação e a seletividade espacial} abordagens dos sistemas territoriais de inovação são os elementos que unem as três perspectivas teóricas. Assim nosso olhar nessa terceira parte do texto constitui o centro da proposição da discussão desse texto, a relação inovação e território a partir de duas teses centrais: 1) as redes territorializadas de inovação e 2) a concentração geográfica que está vinculada a seletividade espacial do capital inovador.

Para a compreensão de ambas precisamos primeiro destacar o conceito de inovação interativa que é comum a três perspectivas teóricas. Esse ponto de vista possui dois pressupostos importantes. Primeiro consideramos a inovação um processo, o que distancia da ideia de um fato isolado. Compreendê-la como um processo exige uma análise que entende o processo inovador desde a concepção da ideia, elaboração, fabricação da inovação e a sua difusão espacial.

56 Segundo, o processo de inovação é essencialmente social. Ou seja, esse percurso do processo inovador está baseado nas interações entre os diversos agentes que estão diretamente associados ao processo inovador. Dizer que é um percurso não significa pensá-lo como linear. o percurso do processo inovador, bem ao contrário disso, é repleto de contradições e de obstáculos que muitas vezes dificultam a sua execução e inviabilizam a concretização da ideia.

57 Parte desses obstáculos está relacionada com o montante de investimento necessário para o desenvolvimento da inovação que acaba por limitar, muitas vezes, as possibilidades de crescimento dessa atividade produtiva em países de renda baixa ou para empresas com menor capacidade de investimento.

Os dois aspectos, o entendimento da inovação como processo e alicerçado em interações, tem no conceito de inovação interativa a sua melhor definição. Inovação interativa é, de acordo com Méndez (1998), uma “perspectiva [que] considera a inovação como o resultado de processos interativos de aprendizagem colectiva" ${ }^{13}$.

59 A ideia central da perspectiva da inovação interativa foi muito bem sintetizada por Lundvall (2005) que afirma que a inovação é um processo de learning by doing, learning by using and learning by interacting, o que reforça a concepção das interações que ocorrem ao longo do processo produtivo.

60 Ainda, a concepção da inovação interativa distancia-se da ideia da inovação como um processo linear que se inicia a partir da realização de uma pesquisa básica avançando 
para a pesquisa aplicada e daí seguindo para o processo produtivo como uma ideia encerrada e fechada.

Diferente dessa perspectiva, a inovação interativa, como fica muito claro na definição de Lundvall (2005), se realiza no processo produtivo a partir da resolução de problemas e interações que envolvem a força de trabalho, os recursos do conhecimento codificado e tácito e a tecnologia disponível.

Isso é ainda mais relevante nos países de renda baixa que como Arocena e Sutz (2003) apontam carecem de um sistema formal de aprendizagem e, nesses países, a inovação ocorre muito mais de forma intersticial.

O aprofundamento das relações sociais diretamente relacionadas com o processo de inovação estabelece uma complexa rede de relações entre os agentes inovadores denominadas nesse texto de redes de inovação $0^{14}$. As redes de inovação são definidas como "relações de cooperação/concorrência gerando sinergias e complementaridades necessárias" ${ }^{15}$ a efetivação do processo de inovação.

O conceito de sinergia é muito utilizado nessa concepção para destacar a importância da aglomeração e das relações de cooperação que se dão no território. Sinergia significa considerar que duas ou mais empresas que trabalham juntas podem atingir um nível de competitividade mais elevado do que se trabalhassem individualmente. Essa abordagem, ainda que interessante do ponto de vista da aprendizagem coletiva, foi utilizado na década de 1980 como justificativa e estímulo ao processo de centralização do capital através da fusão e aquisição de empresas.

65 A sinergia e as relações de cooperação, nessa abordagem, podem ser formais ou informais e se dão entre as empresas e demais instituições locais, como instituições de pesquisa, financeiras, de serviços especializados e intensivos em conhecimento, instituições públicas, dentre outras.

66 As redes de inovação se concretizam através de relações de interação e cooperação e possuem forte vínculo territorial. Maillat (2002) aponta isso ao afirmar que

(...) a localização das atividades não é mais fundada sobre a simples utilização de recursos locais pré-existentes, mas sobre a inserção do estabelecimento no seu meio-ambiente de implantação, para aí estabelecer relações de colaboração e contribuir assim para o seu enriquecimento e desenvolvimento em recursos específicos $^{16}$.

67 Essa concepção que se aproxima da ideia da territorialização da produção inovadora denota uma lógica territorial do sistema de produção que se diferencia da lógica funcional que Maillat (2002) apresenta e estão indicados no quadro 2. 
Quadro 2 - Tipologia de sistemas territoriais de produção

\section{Quadro 2 - Tipologia de sistemas territoriais de produção}

Lógica Funcional

- Organização Hierárquica

Lógica Vertical

Repartição geográfica das funções de maneira a diminuir os custos de produção

Território apenas como suporte

\section{Lógica Territorial}

- Elo forte entre território e empresa

Lógica horizontal

Relações de cooperação e concorrência

Sinergias

Território é ativo

Fonte: Tunes, 2015

68 Na lógica funcional a organização hierárquica identifica que há agentes que são mais importantes no processo de produção da inovação do que outros. Na abordagem evolucionista isso ocorre exatamente com o destaque para a atuação da empresa reconhecida como "núcleo" da inovação. Há, portanto, nesse caso, uma lógica vertical que decorre do menos importante para o mais, aparecendo por cima dessa linha vertical a empresa que tem a função de dirigir as decisões no processo inovador.

Do ponto de vista da localização, na lógica funcional, segundo Maillat (2002), ocorre a divisão territorial da produção tendo como objetivo principal a diminuição de custos de produção. Isso significa dizer que a empresa divide territorialmente a produção de acordo com as etapas da produção (concepção, fabricação, comercialização, etc) pensando na estratégia da diminuição de custos (força de trabalho, transportes, subvenções acordadas, etc).

70 Ao contrário disso, a lógica territorial entende o processo de inovação a partir da horizontalidade em que os diferentes agentes da inovação cooperam entre si sem a determinação de graus de importância. Está presente aqui a ideia da aprendizagem coletiva e há relações de cooperação entre empresas juridicamente distintas que levam a complementação da produção.

71 Em decorrência dessa compreensão da relação território e inovação, a abordagem dos sistemas territoriais de inovação reconhece que as condições materiais e imateriais para o estabelecimento das relações de aprendizagem produzem uma diferenciação territorial.

Com o nível territorial afasta-se a ideia de uma geografia da inovação uniforme; ao contrário, a reflexão teórica aponta para uma capacidade diferenciada dos territórios na organização dos recursos (capital, informação, competitividade, saber-fazer), e dos atores (empresas, institutos, pessoas, etc) necessários à inovação. 17

72 A questão central que une as redes territorializadas de inovação e a seletividade espacial produtora de desigualdades é justamente o que Vale (2009) apontou na citação acima sobre os recursos necessários à inovação. 
73 Acabamos de debater que a inovação interativa depende de relacionamentos entre as empresas o que sobrevaloriza, como já apontamos, especialmente a força de trabalho, os recursos do conhecimento codificado e tácito e a tecnologia disponível.

Esses três recursos - força de trabalho qualificada, conhecimento tácito e codificado e tecnologia - não estão distribuídos no território de forma homogênea. Ao contrário disso, esses recursos estão concentrados em poucos territórios que assim possibilitam o desenvolvimento do processo de inovação.

Vale (2012) discute especialmente as razões da concentração geográfica da inovação de forma multiescalar e destaca três aspectos que a justificam e que reforçam os argumentos que acabamos de apresentar.

76 A primeira, de ordem produtiva, retoma as redes de inovação que já destacamos através das relações de subcontratação e terceirização entre empresas diferentes e que são altamente dependentes das relações de proximidade geográfica. A segunda, no campo da força de trabalho, reforça a qualificação e criatividade da força de trabalho que está presente em poucos territórios. E por fim, a questão tecnológica, que o autor se refere as relações entre território, conhecimento e aprendizagem que são, de acordo com essa abordagem, dependentes de contextos espaciais específicos e impulsionados em locais onde o conhecimento tácito é produzido e circula informalmente entre as pessoas que frequentam esses ambientes.

Daí surgem as expressões utilizadas em algumas pesquisas de regiões ganhadoras, aquelas que possuem os recursos territoriais necessários a produção da inovação, e as regiões perdedoras, compostas pelas regiões em que há carência dessas mesmas condições.

Essas regiões ganhadoras, ou simplesmente as áreas de maior concentração do processo inovador, estão do ponto de vista global localizados em poucos pontos e bastante relacionados com as grandes aglomerações urbanas como as metrópoles. Esse aspecto, da relação entre o urbano e a inovação, abre uma possibilidade ampla de pesquisa que certamente contribuirá para o aprofundamento dessa abordagem.

79 O que se observa, assim, nos estudos empíricos dessas linhas de reflexão é uma marcante concentração geográfica da produção inovadora em toda e qualquer escala geográfica de análise o que colabora na afirmação de que há uma estreita relação entre a inovação e a produção de desigualdades espaciais.

\section{Considerações Finais}

O texto procura apresentar o debate contemporâneo da Geografia da Inovação a partir das três perspectivas teóricas que estão mais presentes nos estudos e pesquisas recentes em diversas áreas do conhecimento como a Geografia.

81 Trata-se de uma discussão alicerçada na relação entre território e inovação que compreende que há a formação de uma rede territorializada que envolve tanto redes locais a da aglomeração geográfica como redes distantes e os fluxos internacionais de capital.

82 A territorialização das redes de inovação em poucos espaços geográficos, o que denota uma seletividade espacial relevante do processo inovador, está relacionada, como vimos anteriormente, aos relacionamentos entre as empresas que dão forma as redes 
de inovação que, por fim, não tem grande mobilidade espacial dada a concentração dos recursos necessários para a produção da inovação.

Esse último aspecto, da concentração geográfica do processo de inovação, configura-se em amplo espaço de pesquisa e aprofundamento teórico e empírico da questão que envolve, como já apontamos antes, a compreensão da relação urbano e inovação.

Ainda, por fim, as redes territorializadas e a seletividade do capital inovador revelam-se ainda como produto, ao mesmo tempo que condição, da reprodução do capital que reforça e mantém em escala ampliada o desenvolvimento geográfico desigual.

\section{BIBLIOGRAFIA}

BENKO, Georges. Economia, Espaço e Globalização. São Paulo, Hucitec, 1995.

BRANDÃO, Carlos. Território e Desenvolvimento. As múltiplas escalas entre o local e o global. Campinas, Ed. da UNICAMP, 2012.

CASSIOLATO, J. E.; LASTRES, H. M. Discussing innovation and development: Converging points between the Latin American school and the Innovation Systems perspective? Globelics Working Papers Series, n.08-02, 2008.

CLAVAL, Paul. Geografia Econômica e Economia. GeoTextos, vol.1, n.1, 2005.

EDQUIST, C. Systems of innovation: technologies, institutions and organizations. London, Pinter, 1997.

FREEMAN, Christopher. The National Systems of Innovation in historical perspective. In Cambrigde Journal of Economics, vol. 19, p.5-24, 1995.

HAGERSTRAND, Torsten. [1962] A propagação de ondas de inovação. Boletim Campineiro de Geografia, Campinas, vol.3, n.02, 2013.

LUNDVALL, Bengt-Ake. National Innovation Systems - Analytical Concept And Development Tool. Dynamics of Industry and Innovation: organization, network and systems. Copenhagen, jun. 2005. Disponível em: http://www.druid.dk/conferences/Summer2005/Papers/Lundvall.pdf. Acesso em 21/01/2014.

MAILLAT, D. Globalização, meio inovador e sistemas territoriais de produção. In Interações. Revista Internacional de Desenvolvimento Local, vol.3, n.4. 2002. Disponível em: http:// site.ucdb.br/public/downloads/9077-vol-3-n-4-mar-2002.pdf. Acesso de 12.11.2013.

MAILLAT, D.; QUÉVIT, M.; SENN, L. (Eds.). Réseaux d'innovation et milieux innovateurs: un pari pour le développement régional. Neuchâtel, GREMI/EDES, 1993.

MENDEZ, Ricardo. Innovación tecnológica y reorganización del espacio industrial: una propuesta metodológica. EURE. Revista Latinoamericana de Estudios Urbano Regionales. Santiago, v.24, n. 73, 1998. Disponível em: http://www.scielo.cl/scielo.php? script=sci_arttext\&pid=S0250-71611998007300002\&lng=es\&nrm=iso. Acesso em 02/03/2012.

MOULAERT, Frank; SEKIA, Farid. Territorial Innovation Models: a Critical Survey. In Regional Studies, vol.37, n.3, p.289-302, 2003 
SCOTT, A.; STORPER, M. Indústria de alta tecnologia e desenvolvimento regional: uma crítica e reconstrução teórica. Espaço e Debates, São Paulo, vol.25, ano VIII, 1988.

STERNBERG, R. Government R\&D expenditure and space: Empirical evidence from five advanced industrial economies. Research Policy, vol. 25, p. 741-58, 1996.

STORPER, Michael. Territorialização numa Economia Global. Possibilidades de Desenvolvimento Tecnológico, Comercial e Regional em Economias Subdesenvolvidas. In LAVINAS et al. Integração, Região e Regionalismo. Rio de Janeiro, Bertrand Brasil, 1994.

STORPER, M.;WALKER, R. The Capital Imperative: territory, technology and industrial growth. New York/Oxford, Backwell, 1989.

SHEARMUR, Richard. Neo-Regionalism and Spatial Analysis: complementary approaches to the Geography of Innovation? Paper. 2008. Disponível em: http://sites.utoronto.ca/isrn/ publications/WorkingPapers/Working08/Shearmur08_neoregionalism.pdf. Acesso em 12/05/2013.

VALE, Mario. Conhecimento, Inovação e Território. Finisterra - Revista Portuguesa de Geografia, vol. XLIV, n.88. Lisboa, 2009. Disponível em: http://www.ceg.ul.pt/finisterra/numeros/ 2009-88/88_01.pdf. Acesso em 01/08/13.

VALE, Mario. Conhecimento, Inovação e Território. Lisboa, Edições Colibri, 2012.

TUNES, R.H. Geografia da Inovação. Território e Inovação no Brasil no século XXI. São Paulo, 2015. Tese (Doutorado) - Faculdade de Filosofia, Letras e Ciências Humanas da Universidade de São Paulo.

\section{NOTAS DE FIM}

1. HAGERSTRAND, 2013 [1962], p.353.

2. STORPER, 1994, p.15.

3. Moulart e Sekia, 2003, p.291.

4. Para o aprofundamento das três perspectivas teóricas indicamos a leitura de Vale (2009), Tunes (2015) e Moulart e Sekia (2003).

5. Benko, 1995, p.141.

6. A referência a grande empresa relaciona-se com o crescimento da produção e a consequente modernização tecnológica. Não possui vínculo, nesse caso, com a quantidade de força de trabalho utilizada.

7. Vale, 2009, p.57

8. MAILLAT, QUÉVIT, SENN, 1993 p.9

9. Storper, 1994, p.17

10. Brandão (2012) não apresenta a crítica específica ao meio inovador, mas a várias abordagens, inclusive do meio, que possuem uma abordagem centrada no desenvolvimento local.

11. BRANDÃO, 2012, p.48

12. CASSIOLATO; LASTRES, 2008, p. 07.

13. MÉNDEZ, 1998, p.19.

14. MÉNDEZ, 1998; MAILLAT, 2002.

15. MAILLAT, 2002, p.11

16. MAILLAT, 2002, p.10

17. VALE, 2009, p.67 


\section{RESUMOS}

A compreensão da relação entre território e inovação constitui-se no objetivo central desse artigo a partir do debate envolvendo três contribuições teóricas que buscam destacar a dimensão geográfica do processo de inovação. A primeira perspectiva é a dos novos espaços industriais da Escola Californiana de Geografia Econômica; a segunda, a dos meios inovadores dos pesquisadores do GREMI (Groupe de Recherche Européen sur les Millieux Innovateurs); a terceira, a dos sistemas nacionais/regionais de inovação que possuem enfoques teórico-metodológicos diferentes. $O$ que une as três perspectivas é a relevância adquirida pelo território usado no processo de inovação e, a partir disto, a emergência das redes de inovação e da seletividade territorial do capital inovador.

Cet article veut comprendre les rapports entre territoire et innovation à partir des débats autour de trois courants théoriques: (i) les nouveaux espaces industriels de l'École Californienne de Géographie Économique ; (ii) les moyens innovateurs de la part des chercheurs du GREMI ; (iii) les systèmes nationaux/régionaux de l'innovation et ses différentes approches. On peut les amalgamer à partir de l'importance du territoire dans le processus d'innovation et, par conséquence, l'émérgence des réseaux d'innovation et de la sélectivité du capital innovateur.

The understanding of the relation between territory and innovation is the central goal of this article based on the debate of three theoretical contributions which together seek to highlight the geographical dimension of the innovation process. The first perspective presented is the new industrial spaces of the Californian School of Economic Geography. The second is the innovative media of the GREMI researchers (Groupe de Recherche Européen sur les Millieux Innovateurs) and the third of the national / regional innovation systems whcich have different theoretical and methodological approaches. What unites the three perspectives and what is highlighted in this text is the relevance that territory (in the sense of territory used) acquires in the process of innovation and, from this perspective, the emergence of innovation networks and the territorial selectivity of innovative capital.

La comprensión de la relación territorio y la innovación es el objetivo central de este artículo basado en la discusión de tres contribuciones teóricas que buscan poner de relieve la dimensión geográfica del proceso de innovación. El primer punto de vista se presenta de los nuevos espacios industriales de la Escuela de Geografía Económica de California. El segundo es el medio innovador del GREMI Investigadores (Groupe Européen de Recherche sur les Millieux innovateurs) y la tercera parte de los sistemas nacional/regional de innovación tienen diferentes enfoques teóricos y metodológicos. Lo que une a los tres puntos de vista y lo que estamos destacando en este texto es la relevancia del territorio (en el sentido de territorio utilizado) adquiere en el proceso de innovación y, desde esta perspectiva, la aparición de las redes de innovación y la selectividad territorial del capital innovador.

\section{ÍNDICE}

Palabras claves: innovación, redes, territorio, método, capitalismo.

Palavras-chave: inovação, redes, território, método, capitalismo.

Mots-clés: innovation, réseaux, territoire, méthode, capitalisme.

Keywords: innovation, network, territory, method, capitalism 


\section{AUTOR}

\section{REGINA TUNES}

Doutora em Geografia Humana, professora da Universidade Metropolitana de Santos e pesquisadora do Laboratório de Estudos Regionais do Departamento de Geografia (FFLCH/USP).

Email: rtunes@usp.br 